\title{
Experts issue guidance on best care for dentures
}

A global task force of academic experts has released new guidelines to address the needs of an ageing population worldwide in tackling inconsistent and contradictory advice on the best care of dentures.

The Global Task Force for Care of Full Dentures, brought together by UK-based charity the Oral Health Foundation, said current recommendations on denture care were often 'confusing' and 'unreliable', while many made claims that were without valid evidence.

It is anticipated that the need for people to have dentures will increase dramatically over the next 30 years as the older population increases with a predicted two billion people aged over 60 by 2050 .

The group of experts including representatives from the Oral Health Foundation and King's College London, have launched a series of guidelines on how to look after dentures. ${ }^{1}$

The project, which received an educational grant from GSK, featured a panel of independent and internationally-recognised experts from the Netherlands, Belgium, Switzerland, Japan and the UK.

Risks associated with poor denture care include inflammation of the mouth, staining, changes in taste and bad breath. It has also been linked to wider health problems such as pneumonia, particularly in frail older people.

The new advice has been summarised in four key steps:

- Brush dentures daily using a toothbrush or denture brush along with a nonabrasive cleaner (not toothpaste as some have been previously instructed)

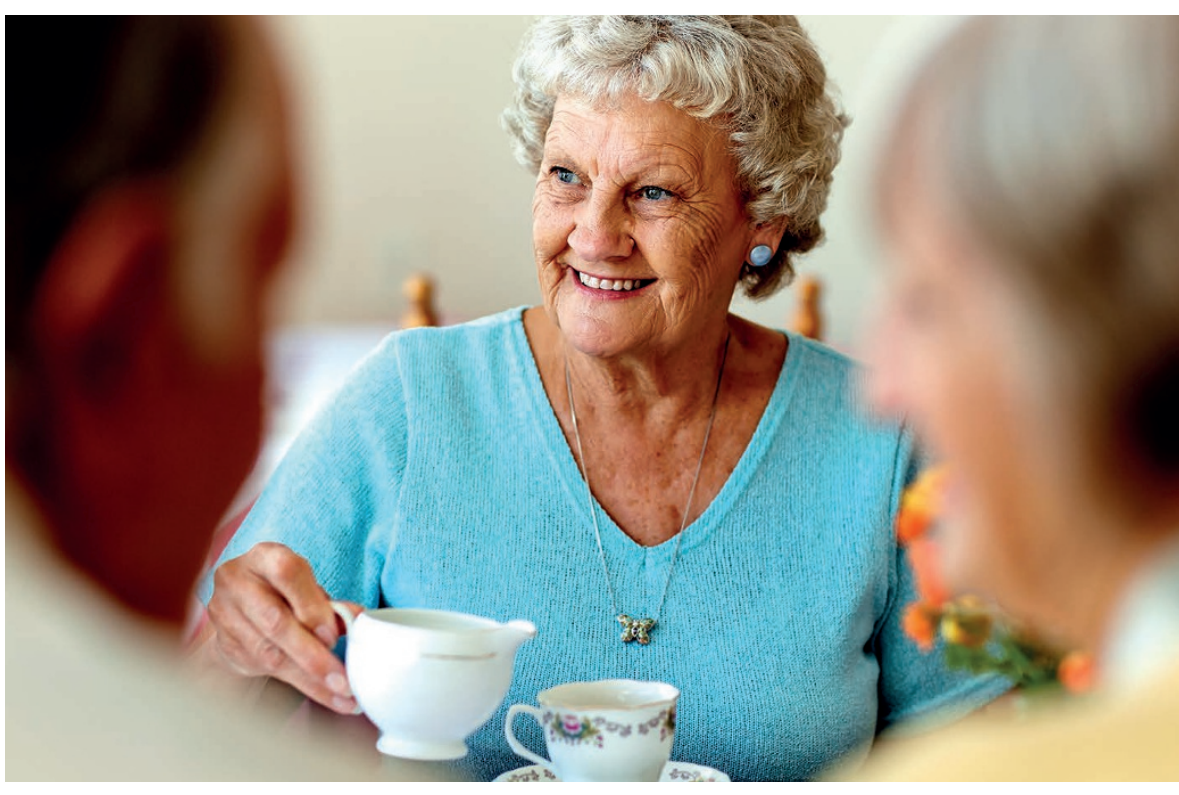

- Soak dentures daily using a denture cleanser to remove more of the bad bacteria and disinfect the dentures

- Take out dentures at night unless there are reasons for leaving dentures in - taking them out overnight will help to relieve any soreness and prevent infection

- Visit a dentist regularly to ensure dentures are being kept in good condition and the mouth is still healthy.

The new guidelines were launched on 7 September 2018 at the FDI World Dental Congress, held in Argentina.

Dr Nigel Carter, Chief Executive of the Foundation, said: 'We have found that people with dentures do not know how they should be cleaning them. Our report shows that denture wearers use everything from soap and water to toothpastes, bleaches and commercial products. But with the variety of recommendations available online and from other sources, it is no surprise that people are confused.

'The amount of inconsistent and often unproven advice about cleaning and maintaining dentures is frightening. Incorrect denture care can pose a real threat to both the oral health and general health of denture wearers.

'We hope these new recommendations can reassure people about the best way to look after their dentures. We will now be working with the NHS, local authorities, dental practices and GPs to help adoption of these guidelines across the UK'

\footnotetext{
Oral Health Foundation. White paper on optimal care and maintenance of full dentures for oral and general health. Available at https://www.dentalhealth.org/ denturecareguidelines (accessed on 17 September 2018).
}

\section{Nearly 900 DCPs risk removal from register over compliance}

As many as 900 dental care professionals (DCPs) could be at risk of removal from the register after they failed to make a compliant CPD statement to dental regulator the General Dental Council (GDC), it has emerged.

All DCPs on the 2013-18 CPD cycle, which ended on 31 July 2018 , were required to make a compliant CPD statement by 28 August 2018, but the GDC has revealed that after the deadline had passed, there were nearly 900 non-compliant DCPs whom the regulator was still trying to contact.

The BDA said it was encouraging DCPs and dental practices to check urgently if they or their staff members reached the end of their CPD cycle this summer and, if so, that they had made their CPD end-of-cycle statement.

Non-compliant DCPs were likely to be taken off the register in the next few weeks if they did not take further action, warned the trade union, and if they continued to work in the practice under such circumstances, this would effectively be illegal practice with additional possible future consequences.

The GDC said it was due to write to all those who had not made a statement and anyone who had made a non-compliant CPD statement to explain the options available for those who wished to remain on the register.

More information is available at www. gdc-uk.org/professionals/cpd. 